\title{
BUSINESS SECTOR, LEVEL OF EDUCATION AND ACCESS TO CREDIT: WHAT INFLUENCES ON VULNERABILITY TO RURAL HOUSEHOLDS POVERTY IN CÔTE D'IVOIRE?
}

\author{
Zrakpa Melaine Ouoya \\ Université Félix Houphouët Boigny Abidjan \\ ouoyamelaine@yahoo.fr
}

\begin{abstract}
Many studies have revealed the importance of taking the ex post and former poor into account in designing sustainable poverty reduction policies. With data from the 2015 household standard of living survey (ENV2015), we use the Chaudhuri, Jalan and Suryahadi model (2002) to measure the vulnerability to poverty of rural households in Côte d'Ivoire. Our work reveals that $34 \%$ of households are vulnerable while $25 \%$ are poor. The analysis of the influence of certain factors on this vulnerability was based on a tobit model. We come to the conclusion that farm and trade households are more vulnerable than those in industry and services. Also, households with a head of at least secondary education are less vulnerable than those whose head is at most at the primary level. Finally, contrary to many studies, we find that access to credit has a bad influence on the vulnerability of rural households to poverty. The origin and use of these rural credits would explain this last relationship.
\end{abstract}

\section{Keywords}

vulnerability; rural; credit; business sector; Côte d'Ivoire

\section{JEL Classification}

C13; I21; R20

\section{Introduction}

The socio-economic environment of developing countries tends to link the social, economic and demographic characteristics of rural households to the possibility for them to remain or to fall into poverty in the near future. These characteristics tend to influence the ex ante poverty of these households given the shocks and risks they face or will face. It is a dynamic conceptualization of poverty, and hence of vulnerability to poverty, which aims to determine the influence of risk and shocks on the future status of household poverty in order to provide a "critical overview to policymakers" (Ajay \& Rana, 2005). Thus, poverty reduction policies must now take into account both ex post poverty reduction measures and also ex ante poverty prevention actions in order to help and assist those who are vulnerable to shocks so that they do not fall into poverty (Azam \& Imai, 2009). Novignon (2010) shows that poverty and vulnerability to poverty are independent concepts. Thus policies directed towards poverty reduction need to take into account the vulnerability of current non-poor households.

The dynamic dimension of poverty that uses risk has attracted interest from the economic literature. Thus, pioneering works like those of Chaudhuri (2003) and Christaensen and Subbarao (2005) define vulnerability as the probability of falling into poverty in the near future while Ligon and Schechter (2003) present it as a low expected utility. Tesliuc and Lindert (2004), referring to consumption, measure it as an not covered exposure to risk. Also, based on these pioneering works, much work has focused on an assessment of vulnerability to poverty and identification of its determinants (Azam \& Imai, 2009, Calvo \& Dercon, 2013). This interest is linked to the fact that traditional measures of poverty do not indicate the degree of risk for 
households to become or remain poor. They can therefore be misleading and misguided in the context of implementing poverty reduction policies (Bah, 2013). According to the World Bank Social Risk Management framework, these policies are linked to three types of risk management strategies: prevention, mitigation and adaptation (Holzmann \& Jorgensen, 2000). Despite the fact that thevulnerability is an emerging concept in the economic literature, there is an insufficient number of case-specific studies of the vulnerability of rural households in developing countries. In addition, the case of the Ivorian economy deserves particular the attention within the global model of studying the poverty situation of developing countries.

Indeed, after independence in 1960, this country has experienced a long period of relative growth and prosperity that many analysts called the ivorian "economic miracle". This growth was supported by commodity prices (coffee and cocoa in particular) in the international market. Unfortunately, in the early 1980s, while some developing economies began a phase of relative growth, the fall in commodity prices led the Ivorian economy into a long phase of recession, accentuated by the sociopolitical turmoil of the 1990s. The economic growth after the 1994 devaluation increased from $5.7 \%$ in 1997 to $-2.7 \%$ in 2000 , and this downward trend continued in subsequent years despite the lull and the slight recovery in 2001. This economic recession, coupled with a socio-political crisis, had a negative impact on the living conditions of households. Indeed, since 1985, Côte d'Ivoire has carried out several surveys (Household Living Standards Survey 1985, 2002, 2008 and 2015) to monitor the evolution of poverty over time. The 1985 survey set the incidence of poverty in Côte d'Ivoire at $10 \%$ and retained 75,000 CFA per individual and per year as the national poverty line. It is this threshold that is updated every year to obtain the 2015 poverty line of 269,000 FCFA. From 1985 to 2008, poverty increased sharply from $10 \%$ to $48.9 \%$, despite a decline in the period 1995 to 1998 following the devaluation of the franc CFA.

In a recent period, that is, from 2008 to 2015, there is a decline in poverty whose incidence has dropped from $48.9 \%$ to $46.3 \%$. According to ENV2015, rural areas are the main provider of poor people in Côte d'Ivoire. In fact, the incidence of poverty is $56.8 \%$ in rural areas compared to $35.9 \%$ in urban areas. However, rural poverty is declining while it is increasing in urban areas. To date, thanks to the normalization of the socio-political situation and the resumption of economic activities, growth has been noted. The completion point of the HIPC initiative, largely conditioned by the implementation of several reforms, was achieved in 2012. The country has thus benefited from a significant reduction in its external debt, the amount of which is estimated at around FCFA 6,500 billion. Although surveys have been regularly conducted by competent institutions to assess the level of expost poverty of households in Côte d'Ivoire, the assessment of ex ante poverty, ie vulnerability to poverty, has not been of real interest, despite the many shocks that households have faced during these recurring crisis. It is therefore necessary to focus on ex ante poverty if it is envisaged to design sustainable poverty reduction strategies in Côte d'Ivoire, hence the value of conducting this research.

The purpose of this work is to contribute to the design of sustainable poverty reduction strategies in Côte d'Ivoire. This research will be conducted as follows: The first section presents the literature review while the second one presents the current poverty situation of the country. The third section reviews the methodology used in presenting the data and the analysis model. The fourth section presents the results of the econometric analysis and the related discussions. The last section will conclude and make policy recommendations for reducing poverty and vulnerability to poverty among rural households in Côte d'Ivoire. 


\section{Review of literature}

In the existing literature, income or consumption expenditure measured over short periods of time (say one year) have been viewed as proxies for the material welfare of households. However, economists recognize that the feeling of well-being in the household depends not only on average income or expenditure, but also on risks, whether idiosyncratic (relating to an individual) or systemic (relating to to an entire community). It is therefore to take into account the risk inherent in the lives of households that researchers have oriented their work towards the study of vulnerability to poverty (Jha et al, 2009). Chaudhuri et al (2002) defined vulnerability to poverty as the "ex ante risk that a household will be poor in the future, regardless of its current state of well-being". An attractive definition of vulnerability to poverty is "the propensity for welfare to suffer a significant shock, bringing the household below a socially defined minimum level" (Alwang, Siegel \& Jorgensen, 2001). Although this definition reflects the spirit of what we mean by vulnerability to poverty, it needs to be more precise if we want to measure vulnerability. Three points require clarification. First, what is meant by "welfare shock"? The measure of well-being most commonly used by economists in this context is consumption per individual (or adult equivalent), although other measures such as income may be used instead. A "shock" of well-being is therefore generally measured as a change in consumption per individual. The shock could be negative or positive, although we are typically affected by shocks in the more traditional sense of harmful events. By focusing on consumption rather than income or assets, we implicitly allow households' coping mechanisms to work. For example, consider a village hit by drought every few years. Households, anticipating periods of drought, store grain in good years for use in bad years. If we use income as a measure of well-being, we will overestimate household welfare in good years and underestimate it during years of drought. By using consumption as an indicator of well-being, we enable households to respond.

Second, what "socially defined minimum level" of well-being is appropriate? Here we generally use a poverty line. Studies of vulnerability to poverty generally use an absolute poverty line.

Third, how can we measure the "propensity to suffer a major shock" from being poor? A good practical way to measure vulnerability is the probability of being poor the following year (Chaudhuri, Jalan \& Suryahadi, 2002), or in the next few years (Pritchett, Shryahadi \& Sumarto, 2000). But how high must this probability of being poor be to enable us to consider the person (or household) as vulnerable? If I have a 1\% probability of being poor next year, am I vulnerable? Or 10 percent? Or 50 percent? The line between those who are vulnerable to poverty and those who are not is arbitrary, but researchers generally use one of two thresholds:

- A probability of being poor by $50 \%$. In this case, a household has at least an equal chance of being poor next year. These households are sometimes called "very vulnerable".

- A probability of being poor from P0 (where P0 is the incidence of poverty). So, if your probability of being poor is higher than $\mathrm{P} 0$, you could be considered vulnerable by this measure. Indeed, this means that you are more likely than the typical household to be poor in the next period. Households whose probability of being poor is greater than P0 but less than $50 \%$ are sometimes classified as "low vulnerability". Households that are less likely to be poor than P0 are sometimes referred to as "non-vulnerable", but this label should not be taken literally because they are likely to be in poverty the following year (or in the next few years). The probability of being poor increases as the time horizon gets longer; a person with a $50 \%$ probability of being poor next year may have a $75 \%$ probability of being poor in at least one of the next two years and a $87.5 \%$ probability of being poor in at least one of the next three years. 
Following the presentation of the instruments for measuring vulnerability to poverty, many studies have set themselves the objective of measuring households' vulnerability to poverty and then identifying its determinants. Novignon (2012) after estimating the vulnerability to household poverty in Ghana, examined the effect of various socioeconomic characteristics on this vulnerability. His results showed that household health status is a determinant of vulnerability to poverty, and this finding provides empirical evidence for Grossman's "health capital" theory (1972a). According to this theory, health is in itself a resource that helps people improve their well-being, as healthy individuals spend much more time working and less in poor health. Similar findings were found by Azam and Imai (2009) who concluded that in Bangladesh, households without education or farming households are probably the most vulnerable to poverty. In the same vein, Novignon (2012) showed that households headed by educated chefs are less vulnerable to poverty. These studies are in line with those of Ligon and Schechter (2003) who found that household health status, household size and educational attainment significantly influence vulnerability to poverty and that households headed by a man are less vulnerable to poverty. The works of Jha et al (2009) in Fiji have highlighted the fact that the distribution of vulnerability differs significantly from the distribution of poverty and that many non-poor have been found to be vulnerable to poverty. Suryahadi and Sumarto (2003) analyzed the influence of the Indonesian crisis on household vulnerability and poverty. According to these authors, the crisis has led to a significant increase in the number of poor households that are vulnerable to poverty. The increase in the number of poor was mainly due to a large increase in the category of the chronically poor (those who are poor and vulnerable). Novignon (2010) showed that about 56\% of households in Ghana are vulnerable while only about $28 \%$ are poor. The implication of this work is that poverty reduction policies must take into account the vulnerability of current non-poor households. Milcher (2010) adapted the model of Chaudhuri, Jalan and Suryahadi (2002) to analyze the vulnerability to poverty in nine countries of South-East Europe and finds that vulnerability differs considerably from poverty because it affects a larger population facing risks. This work has concluded that policies to reduce or prevent poverty require additional targeting of vulnerable households. Swain and Floro (2008) studied the effect of SHG (self-help group) participation on poverty and vulnerability and found that members of SHG had a lower vulnerability than members of a control group. In addition, their study found that poverty contributes about 80 percent of household vulnerability, followed by overall risk.

Thus, in recent years, the analysis of vulnerability to poverty has been of particular interest to researchers. Such comments are supported by the diversity of work whose objective is to assess vulnerability to poverty and / or identify its determinants. The targets of these different works have generally been the populations of developing countries. However, in the West African sub-region, little work has been conducted in this direction, like those of Novignon (2010) and Novignon (2012) on Ghana. From the author's knowledge, no vulnerability to poverty assessment study has been conducted in Côte d'Ivoire. It is to fill this gap that we are realising this analysis. The purpose of this work is to contribute to the reduction of poverty in rural Côte d'Ivoire. It will be for us to answer the following questions all relating to rural households in Côte d'Ivoire: i) Are there more households vulnerable to poverty than poor households? ii) What are the influences of the education level and sector of activity of the head of household on the vulnerability to poverty of households? iii) Does access to credit reduce vulnerability to household poverty?

From these research questions, we emit the following research hypotheses:

H1: Households vulnerable to poverty outnumber poor ones;

H2: Households whose head has a high level of education are less vulnerable; 
H3: Households engaged in agriculture are more vulnerable than others;

H4: Households with access to credit are less vulnerable.

Following the enumeration of our research hypotheses, we present the situation of poverty in Côte d'Ivoire.

\section{State of poverty in Côte d'Ivoire}

At the end of independence, Côte d'Ivoire has experienced two successive decades of unprecedented growth. This growth largely based on the favorable price of cocoa and coffee on the world market, will stop abruptly in the 1980s due to the fall in prices of these products. The country began a long period of unfavorable economic conditions accentuated by successive social and political upheavals. It is at the dawn of this long phase of economic recession that the country will begin in 1985 its first survey on the standard of living of households. These four surveys (1985, 2002, 2008 and 2015) that have been conducted to date have revealed a gradual deterioration in the standard of living of households in Côte d'Ivoire. Thus, the poverty ratio rose from 10\% in 1985 to more than $32.6 \%$ in 2002 (ENV2002). Moreover, with the scarcity of public resources, investments in basic social services (health, education, infrastructure etc.) have fallen considerably, leading to a decrease in the supply of these services. Today, very few Ivorian households have access to social services, which is likely to keep them in a sustainable situation of poverty. To this very dark image was added, from September 2002, the political-military crisis that shook the country for more than a decade. This crisis has not only accentuated the deterioration of the living conditions of households, but has also given rise to new phenomena such as the massive displacement of populations, the destruction of goods, tools of production, social infrastructures etc. not to mention the loss of life and the dislocation of family cells etc.

The improvement of the macroeconomic framework and the easing of the social climate led to the conclusion of a three-year program supported by the Extended Credit Facility covering the period 2009-2011. The effective resumption of financial cooperation led to a real GDP growth rate of $3.8 \%$ in 2009 and $2.4 \%$ in 2010 . At the same time, GDP per capita has grown very slowly by $0.24 \%$ on average per year over the period 2004 to 2010. All these efforts will be once again thwarted by the impact of the post-election crisis of December 2010. In January 2011, the closure of the main BCEAO agency in Abidjan the suspension of banking and export activities of the main agricultural products seriously affected the economic sector. For almost five months (December 2010 to March 2011), the main activities slowed down. The destruction and plundering of many infrastructure hampered production prospects leading to a $5.8 \%$ decline in economic growth. Thanks to the normalization of the socio-political situation and the resumption of economic activities, economic growth has been revived and the completion point of the HIPC initiative, largely conditioned by the implementation of several reforms, was achieved in 2012. The country has thus benefited from a significant reduction in its external debt of about CFAF 6500 billion.

As in previous years, the Household Standard of Living Survey (ENV2015) reveals that poverty is more pronounced in rural than in urban areas. In rural areas, the incidence of poverty is $56.8 \%$ compared with $35.9 \%$ in urban areas. In addition, the contribution of rural populations to poverty is $61.2 \%$ against $38.8 \%$ for urban populations. On the other hand, the evolution of poverty is contrasted from one milieu to another. In fact, while poverty is declining sharply in rural areas (from $62.5 \%$ in 2008 to $56.8 \%$ in 2015), it continues to grow in urban areas (24.5\% in 2002, $29.5 \%$ in 2008 then $35.9 \%$ in 2015). There is therefore a transfer of poverty from rural areas to urban areas. 


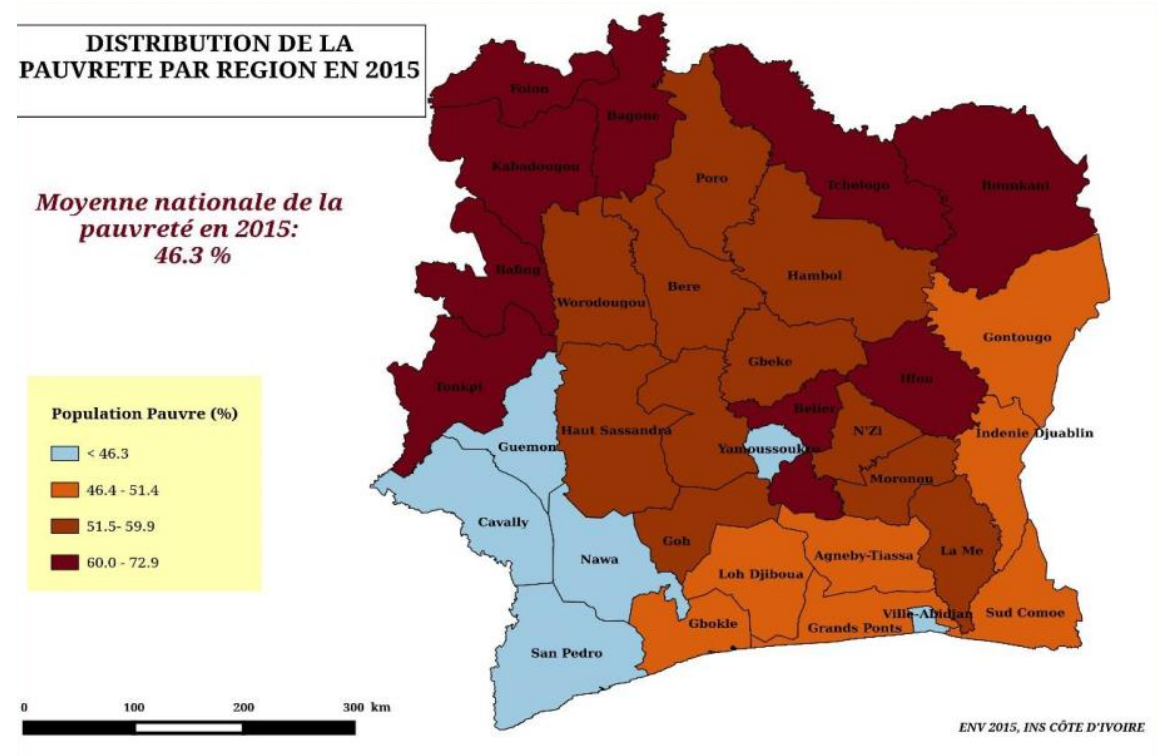

Figure 1 Spatial distribution of poverty in 2015

Source: INS, ENV2015

In 2002, the year in which the socio-political crisis of 2002-2010 began, Côte d'Ivoire had four out of eleven regions for which more than half of the population was poor with more pronounced situations in rural areas. These were Western $(64.4 \%$ and $67.4 \%$ in rural areas), Northeast (56.6\% and $61 \%$ in rural areas), Northwest (51.5\% and $61 \%$ in rural areas) and Central West (50.3\% and $51.5 \%$ in rural areas). In 2008, after six years of crisis, this number rose to 8 out of the 11 strata of which the North $(77.3 \%$ and $85.1 \%$ in rural areas), the West (63.2\% and 67.8\% in rural areas), the West Center (62.9\% and $70.7 \%$ in rural areas), the Northwest (57.9\% and $60.4 \%$ in rural areas), the North Center (57\% and $66.3 \%$ in rural areas), the Center (56\% and $65.7 \%$ in rural areas), the North East $(54.7 \%$ and $59.2 \%$ in rural areas) and the Central East $(53.7 \%$ and $63.1 \%$ in rural areas). The mapping of regional levels of poverty shows that poverty is higher in the north-west border regions in the North-East (from Tonkpi to Bounkani) and lower in the border regions from East to South-West (going from Gontougo to Cavally). Inland regions (non-frontier) have an intermediate level of poverty between these two extremes. Thus, poverty is unequally distributed among the regions of Côte d'Ivoire. The level of poverty varies from $22.7 \%$ in the city of Abidjan to $71.7 \%$ in the Kabadougou region.

Figure 1 shows the distribution of poverty in the Ivorian territory. Table 1 presents the distribution of poverty according to the 2015 Household Living Standards Survey (ENV2015). This table shows that besides the city of Abidjan, the least poor regions are the region of San-Pedro (35.4\%), the region of Nawa (37.4\%), the region of Cavally and the autonomous District of Yamoussoukro (39.4\%). Conversely, in addition to Kabadougou, the poorest regions are Folon (70.1\%), Bafing (69.2\%), Bagoué (68.5\%) and Tchologo (65.6\%). In addition, more than half of the population is poor in 22 of the 33 regions of the study. CTR refers to the contribution of the region concerned to national poverty. Thus, we see that Abidjan, Upper Sassandra, Gbèkè and Tonkpi have the highest contributions to poverty. 
Table 1 Poverty indices by region in 2015

\begin{tabular}{|c|c|c|c|c|c|c|}
\hline \multirow[t]{2}{*}{ Strates } & \multirow{2}{*}{$\frac{\text { Ratio de }}{\mathrm{PO}}$} & \multirow{2}{*}{$\begin{array}{l}\text { pauvreté } \\
\text { CTR }(\%)\end{array}$} & \multirow{2}{*}{$\frac{\text { Gap de }}{\text { P1 }}$} & \multirow{2}{*}{$\frac{\text { pauvreté }}{\text { CTR }(\%)}$} & \multicolumn{2}{|c|}{$\begin{array}{c}\text { Sévérité de } \\
\text { pauvreté }\end{array}$} \\
\hline & & & & & P2 & $\operatorname{CTR}\left(\frac{\circ}{\circ}\right)$ \\
\hline VILLE D'ABIDJAN & 22,7 & 9,3 & 5,7 & 6,6 & 2,1 & 5,1 \\
\hline HAUT SASSANDRA & 54,9 & 7,5 & 19,1 & 7,4 & 8,8 & 6,9 \\
\hline PORO & 54 & 4 & 17,6 & 3,7 & 7,8 & 3,3 \\
\hline GBEKE & 54,9 & 5,3 & 18,8 & 5,2 & 9,3 & 5,2 \\
\hline INDENIE-DJUABLIN & 48,7 & 2,6 & 17,8 & 2,7 & 8,3 & 2,6 \\
\hline TONKPI & 60,6 & 5,7 & 24,5 & 6,6 & 13,1 & 7,2 \\
\hline DISTRICT YAKRO & 39,4 & 1,4 & 12 & 1,2 & 5,2 & 1 \\
\hline GONTOUGO & 51,2 & 3,2 & 17,8 & 3,2 & 8 & 2,9 \\
\hline SAN-PEDRO & 35,4 & 2,7 & 10,7 & 2,4 & 4,9 & 2,2 \\
\hline KABADOUGOU & 71,7 & 1,2 & 31,9 & 1,6 & 17,6 & 1,8 \\
\hline N'ZI & 59,1 & 1,4 & 19,9 & 1,3 & 8,7 & 1,2 \\
\hline MARAHOUE & 53,6 & 4,4 & 18,7 & 4,4 & 9,2 & 4,4 \\
\hline SUD-COMOE & 46,8 & 2,8 & 14,9 & 2,6 & 6,3 & 2,2 \\
\hline WORODOUGOU & 54,5 & 1,4 & 20,6 & 1,5 & 11,3 & 1,7 \\
\hline LÔH-DJIBOUA & 49,6 & 3,4 & 15,9 & 3,1 & 7,5 & 3 \\
\hline AGNEBY-TIASSA & 49,5 & 2,9 & 18,9 & 3,1 & 9,5 & 3,2 \\
\hline GÔH & 53,3 & 4,4 & 24,3 & 5,6 & 14,9 & 7,1 \\
\hline CAVALLY & 41 & 1,8 & 16,8 & 2,1 & 8,8 & 2,2 \\
\hline BAFING & 69,2 & 1,2 & 28,1 & 1,4 & 14,8 & 1,5 \\
\hline BAGOUE & 68,5 & 2,5 & 34,7 & 3,6 & 21,5 & 4,6 \\
\hline BELIER & 61,8 & 2 & 21,1 & 1,9 & 9,7 & 1,8 \\
\hline BERE & 55,8 & 2 & 18 & 1,9 & 8,1 & 1,7 \\
\hline BOUKANI & 61,8 & 1,6 & 21,8 & 1,6 & 10,2 & 1,5 \\
\hline FOLON & 70,1 & 0,6 & 26,3 & 0,6 & 12,7 & 0,6 \\
\hline GBÔKLE & 51 & 2 & 20,9 & 2,3 & 11 & 2,5 \\
\hline GRANDS-PONTS & 48,9 & 3,5 & 20,8 & 4,2 & 11,1 & 4,6 \\
\hline GUEMON & 42,9 & 3,8 & 13,2 & 3,3 & 5,5 & 2,8 \\
\hline HAMBOL & 56,1 & 2,3 & 17,5 & 2 & 8 & 1,9 \\
\hline IFFOU & 60,5 & 1,8 & 18 & 1,5 & 7,4 & 1,3 \\
\hline LA ME & 52,7 & 2,6 & 21,7 & 3,1 & 12,6 & 3,6 \\
\hline NAWA & 37,4 & 3,7 & 10,9 & 3,1 & 4,6 & 2,6 \\
\hline TCHOLOGO & 65,6 & 3 & 29,6 & 3,8 & 17,2 & 4,5 \\
\hline MORONOU & 54,1 & 1,9 & 16,4 & 1,6 & 6,5 & 1,3 \\
\hline Ensemble & 46,3 & 100 & 16,3 & 100 & 8 & 100 \\
\hline
\end{tabular}

\section{Methodology}

\section{Data}

The data in this study come from the 2015 Household Living Standards Survey (ENV2015). The main objective of this survey was to collect information to improve the planning and evaluation of economic and social policies in Côte d'Ivoire.

The universe of this survey is made up of all African households residing in Côte d'Ivoire. The sampling frame used was the General Census of Population and Housing (RGPH2014). As for sampling, it follows a two-stage draw: at the first stage, a proportional allocation drawing of the Census Districts (CD) was carried out in the study strata; in the second degree, a systematic draw of 12 households per CD was carried out. The sample is stratified into three sets and provides significant results for the region and the place of residence, the city of Abidjan and all of Côte d'Ivoire, urban and rural. The size of the sample per stratum varied between 276 and 1,188 households, to take account of the demographic weight of certain regions. The total sample size is 12,900 households for the 33 strata (31 regions plus the city of Abidjan and the Yamoussoukro Autonomous District). Thus, this size makes it possible to guarantee representativeness at the level of each stratum. As part of this search, the database used contains 10475 observations. Descriptive statistics for this study sample are available at the outcome level of our analysis. After presenting our database, we reveal in the following subsection the analysis model. 


\section{Model of analysis}

As Milcher (2010), we use the model of Chaudhuri, Jalan and Suryahadi (2002) to measure vulnerability to household poverty. This model presents vulnerability as exposure to future poverty risk. Thus, vulnerability is the ex-ante risk that a currently non-poor household will fall below the poverty line or a currently poor household will remain poor. The vulnerability level of a household is defined as the probability that the household will find itself consumption-poor in the next time period. This definition includes the difference between the concept of poverty as an ex-post measure and vulnerability as a forward looking ex-ante measure of a household's wellbeing. Vulnerability at the present time depends on the future prospects of household consumption. Thus, current vulnerability can only be estimated but never be observed, unlike poverty. In order to make inferences about a household's future consumption prospects, inter-temporal aspects as well as cross-sectional determinants of the consumption pattern need to be taken into account.

In general, a household's consumption depends on a variety of factors, such as wealth, current income, employment status, educational level and the ability to smooth consumption in the event of income shocks. Each of these factors depends on household characteristics. In addition, the general socio-economic and political environment into which a household is situated plays a role. In this paper we start with the assumption that the possibility of future poverty depends, on the one hand, on expected consumption and, on the other hand, on the volatility of its consumption stream. The reason is that the stability of a household's consumption stream can vary considerably with regard to different household observable characteristics. Therefore, vulnerability to poverty is estimated by using estimated consumption and the estimated variance of household consumption. In the absence of longitudinal data that could directly estimate inter-temporal variance of consumption at the household level, fairly stringent assumptions apply when using cross-sectional data.

Thus, we assume a stochastic process generating the consumption of a household $h$ given by:

$\ln c_{h}=X_{h} \beta+e_{h}$

where $c_{h}$ is per capita consumption expenditure, $X_{h}$ represents a set of observable household characteristics, such as educational achievements and age category of the household head, dwelling characteristics, household size etc., $\beta$ is a vector of parameters and $\varepsilon_{h}$ is the error term that captures idiosyncratic factors, which contribute to per capita consumption level differences for households that seem to be observationally equivalent.

We assume the idiosyncratic shocks to consumption to be identically and independently distributed over time for each household, thus, uncertainty about future consumptions arrives solely from uncertainty about idiosyncratic shocks for each household. This leads to a third assumption, namely that a household's future consumption does not depend on the future structure of the economy.

Given these assumption, we allow the variance of $e_{h}$ to depend on observable household characteristics expressed by:

$\sigma_{e, h}^{2}=X_{h} \theta$

Estimating the variance for each household using the observable household characteristics provides a considerable advantage in this model, which is usually left out in standard poverty assessments, which assumes the variance to be equal across households. Individual consumption volatilities capture better the fact that poorer households face higher consumption volatility than richer households.

The parameters $\beta$ and $\theta$ are estimated using a three-step feasible generalised least squares (FGLS) method. The first step involves estimating equation (1) using the 
ordinary least squares (OLS) procedure. The estimated residuals are then used to estimate:

$\hat{e}_{O L S, h}^{2}=X_{h} \theta+\eta_{h}$

again by means of OLS. By regressing the squared residuals on the same observable household characteristics, we estimate the variance of $e$. In the second step we use the predictions to transform equation (3) as follows:

$\hat{e}_{O L S, h}^{2} / X_{h} \hat{\theta}_{O L S}=\left(X_{h} / X_{h} \hat{\theta}_{O L S}\right) \theta+\eta_{h} / X_{h} \hat{\theta}_{O L S}$

An asymptotically efficient FGLS estimate, $\hat{\theta}_{F G L S}$ can now be estimated by using OLS. $X_{h} \hat{\theta}_{O L S}$ is a consistent estimate of the variance of the idiosyncratic component of household consumption, $\sigma_{e, h}^{2}$. This estimate is then used in the third step to transform equation (1) as follows:

$\ln c_{h} / \hat{\sigma}_{e ; h}=\left(X_{h} / \hat{\sigma}_{e, h}\right) \beta+e_{h} / \hat{\sigma}_{e, h}$

Now an asymptotically efficient FGLS estimate, $\hat{\beta}_{F G L S}$ can be obtained by using OLS. Using the FGLS estimates $\hat{\beta}_{F G L S}$ and $\hat{\theta}_{F G L S}$, the expected log consumption and the expected variance of $\log$ consumption may be calculated for each household $h$ as:

$\hat{E}\left[\ln c_{h} \mid X_{h}\right]=X_{h} \hat{\beta}$

$\widehat{V}\left[\ln c_{h} \mid X_{h}\right]=\hat{\sigma}_{e, h}^{2}=X_{h} \hat{\theta}$

Finally, the vulnerability level of a household $h$ can be computed using the expected $\log$ consumption and the expected variance of log consumption under the assumption that consumption is log-normally distributed. The vulnerability level may be expressed by:

$\hat{v}_{h}=\widehat{\operatorname{Pr}}\left(\ln c_{h}<\ln \mathrm{z} \mid X_{h}\right)=\Phi\left[\ln \mathrm{z}-X_{h} \hat{\beta} / \sqrt{X_{h} \hat{\theta}}\right]$

with $\Phi$ denoting the cumulative density of the standard normal. The estimated vulnerability level is the probability that the expected future consumption level of a household $h$ is lower than the given consumption poverty line $\mathrm{z}$.

As noted above, the merit of this measure of vulnerability is that it can be estimated with cross-sectional data. However, the measure correctly reflects the vulnerability of households if and only if the distribution of consumption across households, given the characteristics of these households over time represents a time series variation of household consumption. As a result, this measure requires a large sample in which households experience good times and others suffer from some negative shocks.

To estimate the determinants of the probability of being poor, we make use of the tobit model:

$\hat{v}_{h}=\alpha_{0}+\alpha_{1} C A_{h}+\alpha_{2} F W_{h}+\alpha_{3} E L_{h}+\alpha_{4} A S_{h}+\alpha_{5} F A_{h}+\alpha_{5} \operatorname{Cred}_{h}+\alpha_{6} H H S_{h}+$ $\alpha_{7} M N_{h}+\mu_{h}$

where $\hat{v}_{h}$ represents the vulnerability to household $h$ poverty. $C A_{h}, H H S_{h}$ are binar variables representing the age group (younger age of 35; age between 35 and 55 and age over 55) and the sex of the head of household ( 0 for leaders who are women and 1 for men). $F W_{h}$ is a binary variable with a value of 1 if the head of household has a fulltime job and 0 if no. $E L_{h}$ and $A S_{h}$ are categorical variables that indicate the level of education and the sector of activity in which the head of household operates. Four levels of education are chosen: lack of education level, primary level, secondary level and university level. Concerning the variable $A S_{h}$, it takes 4 values, namely 1 for agriculture, 2 for industry, 3 for trade and 4 for services. $F A_{h}$ and $\mathrm{Cred}_{h}$ are binarious variables representing the fact that the household has received family assistance and has received a credit during the last twelve months. Variable $M N_{h}$ refers to the number of males individual in the household $h$. The dependent variable is as follows:

$$
\begin{gathered}
\hat{v}_{h}=\hat{v}_{h}^{*} \text { when } \hat{v}_{h}^{*}>0 \\
\hat{v}_{h}=0 \text { when } \hat{v}_{h}^{*} \leq 0
\end{gathered}
$$

The coefficients $\alpha_{1}, \ldots, \alpha_{7}$ provide an appropriate adjustment to obtain consistent estimates of the effects of changes in the explanatory variables on $\hat{v}_{h}$ (we use $V u l_{h}$ 
instead of $\hat{v}_{h}$ as dependant variable for the rest of the study) for those with a vulnerability to poverty upper than 0 and also indicate the proportion of the total effect due to induced changes in behaviour of those with a probability to be poor in near futur is greater than zero (Berndt, 1991).

\section{Results and discussions}

We start by giving the descriptive statistics of our analysis sample which contains 10475 observations. Table 2 presents these statistics. We can see that the average of the dependent variable ( $\mathrm{Vul}$ ) is $24.5 \%$. This value does not describe the percentage of people vulnerable to poverty according to Chaudhuri et al (2002). It is table 5 below that gives us this information. The CA variable shows that heads of households are mostly young, with $47 \%$ of them under 35 years of age. Then come the heads of households between 35 and 55 years old with $40 \%$ of the workforce. The level of education is very low in rural Côte d'Ivoire. In fact, more than three-fifths of rural household heads have no level of education and only $1 \%$ have been able to reach university level. The finding is the same at the level of the distribution of the heads of household according to the sector of activity. Nearly three quarters are in agriculture, the others being evenly distributed in commerce, services and industry. The crossdivision of households according to the level of education and the sector of activity of the chief is presented in table 3 below. It can be seen that heads of households with no formal education are predominantly present in agriculture with $78 \%$ of their total workforce. The same is true for chiefs at primary and secondary level, with $71 \%$ and $57 \%$ of those in both categories. Also, the higher the level of education, the less interest in agriculture. On the other hand, top-level chiefs are more trade-oriented with $63 \%$ of the workforce.

Table 2 Descriptive statistics of analysis model variables

\begin{tabular}{|c|c|c|c|c|}
\hline Estimation samp & le tobit & Numb & $r$ of obs & 10475 \\
\hline Variable & Mean & Std. Dev. & Min & Max \\
\hline Vul & .2454498 & .2607339 & .001918 & 1 \\
\hline \multicolumn{5}{|c|}{ CA } \\
\hline 55 & .4025776 & .4904404 & 0 & 1 \\
\hline 105 & .1328878 & .3394697 & 0 & 1 \\
\hline 1. FW & .4636754 & .4987026 & 0 & 1 \\
\hline \multicolumn{5}{|c|}{\begin{tabular}{l|l} 
EL I \\
\end{tabular}} \\
\hline 1 & .2044869 & .4033454 & 0 & 1 \\
\hline 2 & .1759427 & .3807896 & 0 & 1 \\
\hline 3 & .0168019 & .1285348 & 0 & 1 \\
\hline \multicolumn{5}{|c|}{ AS I } \\
\hline 2 & .0600477 & .2375866 & 0 & 1 \\
\hline 3 & .0462053 & .2099394 & 0 & 1 \\
\hline 4 & .0618616 & .2409155 & 0 & 1 \\
\hline 1.FA & .0296897 & .1697381 & 0 & 1 \\
\hline 1. Cred & .9217184 & .2686271 & 0 & 1 \\
\hline 1.HHS & .8421957 & .3645748 & 0 & 1 \\
\hline MN & 1.543389 & 1.06038 & 0 & 12 \\
\hline
\end{tabular}

Table 3 Distribution of the population according to EL and AS

\begin{tabular}{rr|rrrr|r}
\hline & & \multicolumn{5}{c}{ lagr 2Ind 3Cce 4Serv } \\
\hline Educ Level & 1 & 2 & 3 & 4 & Total \\
\hline 0 & $\mid$ & 83,241 & 6,201 & 9,728 & 6,875 & 106,045 \\
& $\mid$ & 78.50 & 5.85 & 9.17 & 6.48 & 100.00 \\
& & 71.77 & 56.88 & 67.32 & 42.86 & 67.38 \\
\hline 1 & 19,802 & 2,342 & 2,886 & 2,797 & 27,827 \\
& & 71.16 & 8.42 & 10.37 & 10.05 & 100.00 \\
\hline
\end{tabular}




\begin{tabular}{|c|c|c|c|c|c|c|}
\hline & I & 17.07 & 21.48 & 19.97 & 17.44 & 17.68 \\
\hline \multirow[t]{3}{*}{2} & I & 12,274 & 2,313 & 1,795 & $5,063 \quad$ & 21,445 \\
\hline & I & 57.23 & 10.79 & 8.37 & $23.61 \mid$ & 100.00 \\
\hline & i & 10.58 & 21.22 & 12.42 & 31.57 । & 13.63 \\
\hline \multirow[t]{3}{*}{3} & I & 671 & 45 & 41 & $1,304 \quad$ & 2,061 \\
\hline & I & 32.56 & 2.18 & 1.99 & $63.27 \quad$ & 100.00 \\
\hline & I & 0.58 & 0.41 & 0.28 & $8.13 \mid$ & 1.31 \\
\hline \multirow[t]{4}{*}{ Total } & I & 115,988 & 10,901 & 14,450 & 16,039 & 157,378 \\
\hline & 1 & 73.70 & 6.93 & 9.18 & 10.19 & 100.00 \\
\hline & I & 100.00 & 100.00 & 100.00 & 100.00 & 100.00 \\
\hline & & Pearson & chi2 (9) & $1.4 e+04$ & $\operatorname{Pr}=0.000$ & \\
\hline
\end{tabular}

Source: Our calculations based on ENV2015 data

As we continue our analysis, we can see that credit is available in rural areas since $92 \%$ of households received a loan during the twelve months preceding the survey. It should be noted, however, that the main source of credit in rural Côte d'Ivoire is the informal sector, which accounts for nearly 85 per cent of the total number of loans granted to rural people. The formal and semi-formal sector are at around 15 percent supply as shown in Table 4. These results are in line with those of Ouoya (2018), which shows that more than three quarters of loans in Ivorian rural areas are offered in the informal market, as banks have a small contribution in providing this market with credit.

It should also be noted that $84 \%$ of heads of households are men and the remaining $15 \%$ are women.

Table 4 Distribution of rural credits by origin

\begin{tabular}{r|rrr}
\hline \multicolumn{1}{c}{$\begin{array}{r}\text { auprès de quel } \\
\text { organisme }\end{array}$} & Freq. & Percent & Cum. \\
\hline banque & 746 & 4.14 & 4.14 \\
institution de crédit & 401 & 2.23 & 6.37 \\
fonds sociaux & 44 & 0.24 & 6.61 \\
coopec & 49 & 0.27 & 6.88 \\
autre imf & 140 & 0.78 & 7.66 \\
tontine & 368 & 2.04 & 9.70 \\
particulier & 13,517 & 75.03 & 84.73 \\
coopérative/gvc & 1,130 & 6.27 & 91.00 \\
autres & 1,621 & 9.00 & 100.00 \\
\hline Total & 18,016 & 100.00 & \\
\multicolumn{4}{c}{ Source: Our calculations based on ENV2015 data }
\end{tabular}

The poverty rate in this sample is $25.78 \%$. In this context, according to Chaudhuri et al (2002), all households with a poverty likelihood greater than $25.75 \%$ are considered vulnerable to poverty. Thus, $34.45 \%$ of households have been identified as vulnerable to poverty. The number of households vulnerable to poverty is greater than that of poor households and these results are consistent with many studies on poverty and vulnerability to poverty (Chaudhuri et al, 2002, Novignon, 2010).

Table 5 Population distribution by poverty and vulnerability

\begin{tabular}{|c|c|c|c|c|}
\hline \multicolumn{5}{|c|}{ pauvreté } \\
\hline VUL & I & 0 & 11 & Total \\
\hline \multirow[t]{3}{*}{0} & 6,2 & 279 & 5841 & 6,863 \\
\hline & 91. & 49 & $8.51 \mid$ & 100.00 \\
\hline & 80. & .73 & $21.65 \mid$ & 65.52 \\
\hline \multirow[t]{3}{*}{1} & 1,4 & 199 & 2,113 & 3,612 \\
\hline & 41. & 50 & $58.50 \quad \mid$ & 100.00 \\
\hline & 19. & 27 & $78.35 \quad$ & 34.48 \\
\hline \multirow[t]{3}{*}{ Total } & 7,7 & 778 & $2,697 \quad$ & 10,475 \\
\hline & 74. & 25 & 25.75 & 100.00 \\
\hline & 100. & 00 & $100.00 \quad$ & 100.00 \\
\hline \multirow{5}{*}{ likelihood } & earson ch & ii2(1) & $3.1 e+03$ & $\operatorname{Pr}=0.000$ \\
\hline & l-ratio ch & $112(1)$ & $3.1 e+03$ & $\operatorname{Pr}=0.000$ \\
\hline & Cramé & r's V & 0.5434 & \\
\hline & & gamma & 0.8762 & $\mathrm{ASE}=0.006$ \\
\hline & Kendall's & tau-b & 0.5434 & $\mathrm{ASE}=0.009$ \\
\hline
\end{tabular}




\begin{aligned} & Fisher's exact $= 0.000 \\ & 1$-sided Fisher's exact $= 0.000 \\ &$\hline\end{aligned}

Source: Our calculations based on ENV2015 data

Following the presentation of the descriptive statistics of our variables, some specification tests were performed to select the appropriate model. We have two models at this stage. The first model (saved one) contains a CA variable as presented earlier. The second model, for its part, directly takes into account the age of the head of the household through a variable called "age". We compared the specification measures of these two models after performing the preliminary regressions. The results are available in Table 7. Using the AIC (Akaike's information criterion, 1973), the model with the smallest value of this indicator has the best specification. In the test, its value is divided by $\mathrm{N}$, the number of observations. As for the Bayesian information criterion (BIC), it has been proposed by Raftery (1995) and others to compare nested and non-nested models. Because the BIC imposes a larger penalty for the number of parameters in a model, it favors the simpler model compared to the AIC measure. The BIC statistic is defined in at least three ways and regardless of the version chosen, the result is the same. Raftery (1995) suggested these guidelines to strengthen the evidence base for one model over another based on a BIC difference:

Table 6 Analysis Model Selection with Raftery (1995) Guide

\begin{tabular}{c|l}
\hline Absolute difference & Evidence \\
\hline 0 to 2 & Weak \\
2 to 6 & Positive \\
6 to 10 & Strong \\
$>10$ & Very strong \\
\hline Source: Long, S.J., Freese, J. (2014), Regression Models for Categorical \\
Dependent Variables in Stata, 3rd edition, Texas, Stata Press
\end{tabular}

The BIC difference between these two models is 177.6 in favor of the model containing the CA variable. The test gives a very strong preference for this model and is therefore used as our analysis model. So the rest of our analysis was done with this model containing the CA variable. The following table presents our regression first results.

Table 7 Result of specification tests of both models

\begin{tabular}{|c|c|c|c|c|}
\hline 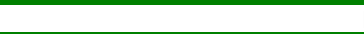 & I & Current & Saved & Difference \\
\hline \multicolumn{5}{|l|}{ Log-likelihood } \\
\hline Model & i & 4313.446 & 4406.875 & -93.429 \\
\hline Intercept-only & 1 & -781.812 & -781.812 & 0.000 \\
\hline \multicolumn{5}{|l|}{ Chi-square } \\
\hline$D(d f=10461 / 10460 / 1)$ & i & -8626.892 & -8813.750 & 186.858 \\
\hline $\operatorname{LR}(\mathrm{df}=12 / 13 /-1)$ & 1 & 10190.517 & 10377.375 & -186.858 \\
\hline \multicolumn{5}{|l|}{ R2 } \\
\hline McFadden & i & 6.517 & 6.637 & -0.120 \\
\hline McFadden (adjusted) & । & 6.499 & 6.618 & -0.118 \\
\hline Cox-Snell/ML & | & 0.622 & 0.629 & -0.007 \\
\hline Cragg-Uhler/Nagelkerke & । & 4.486 & 4.534 & -0.048 \\
\hline \multicolumn{5}{|l|}{$\mathrm{IC}$} \\
\hline AIC & | & -8598.892 & -8783.750 & 184.858 \\
\hline AIC divided by $\mathrm{N}$ & i & -0.821 & -0.839 & 0.018 \\
\hline BIC $(\mathrm{df}=14 / 15 /-1)$ & | & -8497.297 & -8674.899 & 177.601 \\
\hline \multicolumn{5}{|l|}{ Variance of } \\
\hline e & | & 0.026 & 0.025 & 0.000 \\
\hline Difference of 177.601 in & $\mathrm{BIC}$ & provides & strong su & Dort for saved model. \\
\hline
\end{tabular}

Source: Our calculations based on ENV2015 data

Table 8 presents the results of the regression of the selected analysis model. The coefficients of the age group variable for the head of the household show that all other 
things being equal and taking as a reference heads under 35 years of age, households headed by a leader whose age is between 35 and 55 years of age have a $1.25 \%$ increase in the probability of being poor, while those whose head is over 55 years of age see their probability of being poor decrease by $7.6 \%$. Thus, households with an older head are less vulnerable to poverty than households headed by young people or adults. The difference in social and physical capital between old and young could explain this difference in vulnerability status to poverty. Indeed, in rural Côte d'Ivoire, people over 55 years old hold various assets (agricultural land, family courts, livestock etc.) that are used as a means of covering shocks. This theory is consistent with the work of Moser (1998) who defines assets as means of resistance against vulnerability. Vulnerability is therefore closely linked to ownership of assets. Production and exchange activities create assets and, if necessary, can be transformed into production inputs or directly used for consumption. Thus, reducing assets increases vulnerability, although this may not be visible. Thus, according to Moser (1996), "individuals and households ... mobilize their assets to protect their standard of living in the face of the economic crisis". In addition, people over 55 are very often respected patriarchs with often mature children. These mature children financially support and assist the family. This diversified assistance could contribute to reducing the vulnerability of these households. Moreover, the variable FA confirms this theory since households receiving family assistance during the last twelve months preceding this survey have their probability of being poor reduce by 8 percent, all things being equal. The variable FW that identifies the employment status of the head of household (full-time or non-fulltime employment) reveals that households headed by full-time workers are less vulnerable than others on equal terms. Indeed, the provision of a full-time job means the regular receipt of a salary that can serve as a buffer in case of shock.

The HHS variable, which refers to the sex of the household head, shows that maleheaded households are less vulnerable than those headed by women, all other things being equal. There is a sharp 13 percent drop in the probability of being poor from a woman-headed household to a male-headed household on equal terms. This is consistent with the work of Ligon and Schechter (2003). The variable MN reveals that increasing the number of men (male) in the household increases vulnerability to poverty. In the Ivorian rural area, young men very often live maritally at an early age. These young couples are very fertile and also quickly increase the parental family unit in which they remained residents. The inclusion of all these people makes the household vulnerable to poverty. This could explain the positive relationship between the number of men in the household and the status of vulnerability to poverty.

Table 8 Result of tobit model regression

\begin{tabular}{|c|c|c|c|c|c|c|c|c|}
\hline & I & $\mathrm{b}$ & $t$ & $P>|t|$ & bStdX & bStdY & bStdXY & SDofX \\
\hline \multicolumn{9}{|l|}{$\mathrm{CA}$} \\
\hline 55 & । & 0.0125 & 3.529 & 0.000 & 0.006 & 0.048 & 0.023 & 0.490 \\
\hline 105 & | & -0.0764 & -15.417 & 0.000 & -0.026 & -0.293 & -0.099 & 0.339 \\
\hline \multirow[t]{2}{*}{ 1.FW } & 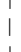 & -0.0163 & -5.113 & 0.000 & -0.008 & -0.062 & -0.031 & 0.499 \\
\hline & \multicolumn{8}{|c|}{ EL } \\
\hline 1 & I & 0.0200 & 4.882 & 0.000 & 0.008 & 0.077 & 0.031 & 0.403 \\
\hline 2 & I & -0.1311 & -30.051 & 0.000 & -0.050 & -0.503 & -0.191 & 0.381 \\
\hline \multirow[t]{2}{*}{3} & i & -0.0493 & -3.978 & 0.000 & -0.006 & -0.189 & -0.024 & 0.129 \\
\hline & । & & & & & & & \\
\hline \multicolumn{9}{|l|}{ AS } \\
\hline 2 & I & -0.1196 & -17.923 & 0.000 & -0.028 & -0.459 & -0.109 & 0.238 \\
\hline 3 & I & 0.0217 & 2.859 & 0.004 & 0.005 & 0.083 & 0.017 & 0.210 \\
\hline 4 & I & -0.0340 & -5.140 & 0.000 & -0.008 & -0.131 & -0.031 & 0.241 \\
\hline & 1 & & & & & & & 177 \\
\hline 1.FA & I & -0.0816 & -8.358 & 0.000 & -0.014 & -0.313 & -0.053 & 0.170 \\
\hline 1.Cred & I & 0.0490 & 8.270 & 0.000 & 0.013 & 0.188 & 0.050 & 0.269 \\
\hline 1. HHS & I & -0.1309 & -28.387 & 0.000 & -0.048 & -0.502 & -0.183 & 0.365 \\
\hline
\end{tabular}




\begin{tabular}{r|rrrrrrr}
\hline MN | & 0.1809 & 118.062 & 0.000 & 0.192 & 0.694 & 0.736 & 1.060 \\
constant I & 0.0745 & 9.764 & 0.000 &. &. &. & . \\
\hline
\end{tabular}

Source: Our calculations based on ENV2015 data

Regarding the level of education of the head of the household, there is a relative equality between the vulnerability status of households headed by a leader with no level and a leader with primary level. On the other hand, households headed by high school or above are less vulnerable than those with no level, on equal terms. This result is similar to the conclusion of the work of Azam and Imai (2009) who found that households without education are probably the most vulnerable to poverty.

The sector of activity of the head of household is taken into account through the categorical variable AS as presented above. The vulnerability status of households operating in agriculture is approximately the same as those in trade (a slight increase of $2 \%$ from an agricultural household to a shopkeeper household) all things being equal. On the other hand, farm households are more vulnerable to poverty than their peers in industry and services. The work of Azam and Imai (2009) reaches the same conclusion that farm households are more vulnerable to poverty. We use the prediction tables here to assess the probability of becoming poor according to the educational level (EL variable) and the leader's activity category (AS variable). By making these discrete changes on these two variables, the question about the value of the other variables arises. According to Long et al (2014), the local mean of these variables is more realistic than the overall mean within the sample. This local average is more appropriate because it takes into account the specific characteristics of the modalities of the predictor variables. The prediction tables are presented in Tables 9, 10 and 11 below.

Table 9 Prediction of the probability of becoming poor according to EL

\begin{tabular}{|c|c|c|c|c|c|c|c|c|}
\hline & 1 & EL & Pr_PO & se & $\mathrm{z}$ & $\mathrm{p}$ & 11 & ul \\
\hline 1 & 1 & 0 & 0.265 & 0.002 & 130.201 & 0.000 & 0.261 & 0.269 \\
\hline 2 & 2 & 1 & 0.285 & 0.004 & 81.336 & 0.000 & 0.278 & 0.292 \\
\hline 3 & 31 & 2 & 0.134 & 0.004 & 35.327 & 0.000 & 0.127 & 0.142 \\
\hline 4 & 1 & 3 & 0.216 & 0.012 & 17.736 & 0.000 & 0.192 & 0.240 \\
\hline \multicolumn{9}{|c|}{ Specified values of covariates } \\
\hline & I & 55. & 105. & 1. & 2. & 3. & 4. & 1. \\
\hline & | & $\mathrm{CA}$ & $\mathrm{CA}$ & FW & AS & AS & AS & FA \\
\hline \multirow{3}{*}{\multicolumn{2}{|c|}{ Current }} & .403 & .133 & .464 & .06 & .0462 & .0619 & .0297 \\
\hline & & 1 . & 1. & & & & & \\
\hline & & Cred & HHS & MN & & & & \\
\hline Current & $=1$ & .922 & .842 & 1.54 & & & & \\
\hline
\end{tabular}

Source: Our calculations based on ENV2015 data

Table 10 Vulnerability prediction by business sector

\begin{tabular}{|c|c|c|c|c|c|c|c|}
\hline I & AS & Pr_PO & $\mathrm{se}$ & $z$ & $\mathrm{p}$ & 11 & ul \\
\hline 11 & 1 & 0.254 & 0.002 & 148.518 & 0.000 & 0.250 & 0.257 \\
\hline 21 & 2 & 0.134 & 0.006 & 20.818 & 0.000 & 0.121 & 0.147 \\
\hline 31 & 3 & 0.275 & 0.007 & 37.385 & 0.000 & 0.261 & 0.290 \\
\hline 41 & 4 & 0.220 & 0.006 & 34.438 & 0.000 & 0.207 & 0.232 \\
\hline \multicolumn{8}{|c|}{ Specified values of covariates } \\
\hline $\mid$ & 55. & 105. & 1. & 1. & $2 \cdot$ & 3. & 1 . \\
\hline । & CA & $\mathrm{CA}$ & FW & EL & EL & EL & $\mathrm{FA}$ \\
\hline \multirow{3}{*}{$\begin{array}{ll}\text { Current } & \mid \\
& \end{array}$} & .403 & .133 & .464 & .204 & .176 & .0168 & .0297 \\
\hline & 1 . & 1 . & & & & & \\
\hline & Cred & HHS & MN & & & & \\
\hline Current | & .922 & .842 & 1.54 & & & & \\
\hline
\end{tabular}

Source: Our calculations based on ENV2015 data 
Table 11 Prediction of vulnerability to poverty according to EL and AS

\begin{tabular}{|c|c|c|c|c|c|c|c|c|c|}
\hline & 1 & EL & AS & $\mathrm{Pr} \_\mathrm{PO}$ & $\mathrm{se}$ & $\mathrm{z}$ & $\mathrm{p}$ & 11 & ul \\
\hline 1 & I & 0 & 1 & 0.274 & 0.002 & 128.309 & 0.000 & 0.269 & 0.278 \\
\hline 2 & | & 0 & 2 & 0.154 & 0.007 & 23.272 & 0.000 & 0.141 & 0.167 \\
\hline 3 & | & 0 & 3 & 0.295 & 0.007 & 39.533 & 0.000 & 0.281 & 0.310 \\
\hline 4 & I & 0 & 4 & 0.240 & 0.007 & 36.236 & 0.000 & 0.227 & 0.252 \\
\hline 5 & I & 1 & 1 & 0.294 & 0.004 & 81.866 & 0.000 & 0.287 & 0.301 \\
\hline 6 & I & 1 & 2 & 0.174 & 0.007 & 25.249 & 0.000 & 0.160 & 0.187 \\
\hline 7 & | & 1 & 3 & 0.315 & 0.008 & 38.902 & 0.000 & 0.299 & 0.331 \\
\hline 8 & I & 1 & 4 & 0.260 & 0.007 & 35.771 & 0.000 & 0.245 & 0.274 \\
\hline 9 & | & 2 & 1 & 0.142 & 0.004 & 36.381 & 0.000 & 0.135 & 0.150 \\
\hline 10 & I & 2 & 2 & 0.023 & 0.007 & 3.043 & 0.002 & 0.008 & 0.037 \\
\hline 11 & I & 2 & 3 & 0.164 & 0.008 & 20.322 & 0.000 & 0.148 & 0.180 \\
\hline 12 & 1 & 2 & 4 & 0.108 & 0.007 & 16.039 & 0.000 & 0.095 & 0.122 \\
\hline 13 & 1 & 3 & 1 & 0.224 & 0.012 & 18.426 & 0.000 & 0.200 & 0.248 \\
\hline 14 & | & 3 & 2 & 0.105 & 0.014 & 7.579 & 0.000 & 0.078 & 0.132 \\
\hline 15 & 1 & 3 & 3 & 0.246 & 0.014 & 17.304 & 0.000 & 0.218 & 0.274 \\
\hline 16 & I & 3 & 4 & 0.190 & 0.014 & 13.773 & 0.000 & 0.163 & 0.217 \\
\hline \multirow[t]{3}{*}{ Specified V } & $\mathrm{Val}$ & Lues & of $\mathrm{COV}$ & iates & & & & & \\
\hline & 1 & & 55. & 105. & 1 & 1 & 1 & 1 & \\
\hline & । & & $\mathrm{CA}$ & $\mathrm{CA}$ & FW & $\mathrm{FA}$ & Cred & HHS & MN \\
\hline Current & 1 & & .403 & .133 & .464 & .0297 & .922 & .842 & 1.54 \\
\hline
\end{tabular}

Thus, in Tables 9, the other variables being maintained at their local average, only households whose head has no education and those whose head is at the primary level are vulnerable to poverty with $26.5 \%$ and $28.5 \%$ respectively. In the business sector, households operating in agriculture and trade are vulnerable. Combining these two variables, we find that among households whose head has no level of education, only those who practice in agriculture and commerce are vulnerable with a respective probability of $27.4 \%$ and $29.5 \%$. For primary-level households, those engaged in agriculture, trade and services are vulnerable. On the other hand, when the head of household has reached the secondary and higher level, whatever the business sector in which the household operates, it is not vulnerable to poverty. Thus, the higher the education level of the household head, the less vulnerable the household is to poverty. We are now interested in the influence of access to credit (variable Cred). Contrary to the findings of many works, we find that access to credit increases the vulnerability of rural households to poverty.

Indeed, according to Elis (2010), broader access of individuals and firms to credit will contribute to an increase in return on investment productivity. Eswaran and Kotwal (1990) argue that having access to credit could reduce households' vulnerability to negative shocks by increasing their ability to smooth consumption during difficult times. Also, this availability of credit allows households to undertake risky investments and helps strengthen the productive assets of households. When producers are unable to make the necessary initial investments or bear the additional risk, they must give up their productivity and no longer be able to improve their income and well-being (Besley, 1995, Boucher et al. 2008). In addition, without adequate access to loans or insurance, producers facing negative shocks such as drought, disease or significant price declines may lose some of the few assets they own (Diagne \& Zeller, 2001). For example, producers with access to well-designed credit, savings and insurance services may have capital to finance the inputs, labor and equipment they need to generate income; they can afford to invest in riskier but more profitable companies and asset portfolios; and may adopt more effective strategies to stabilize their food intake (Zeller et al, 1997). However, the work of Beck, et al. (2008) showed that increasing access to household credit does not have a positive impact on growth. Overall, greater access to 
financial services offers opportunities to improve agricultural production, food security and the economic vitality of communities and entire nations. How can we explain the positive relationship between access to credit and vulnerability to poverty? To answer this question, identify the main source (s) of rural credit in Côte d'Ivoire. In the analysis of the rural credit market in Côte d'Ivoire, it has been found that the formal and semiformal sectors are almost absent as they offer less than 15 percent for rural credit. The informal sector is therefore the main provider of rural credit (ENV2015). For Zeller et al (1997), only quality credit services could enable rural people to make productive investments and stabilize their consumption. Unfortunately, despite the fact that informal credit is widely available in rural areas, it should be noted that it has perverse effects of imprisonment of plaintiffs in a sort of vicious circle. Indeed, Wen Tie-yun (2001) argues that a growing number of poor people in rural China have been trapped in the debt cycle and have been forced to provide labor power to lenders in exchange for the repayment of their loans. In a report submitted to the Monetary Policy Committee of the People's Bank of China (PBOC) and the Central Bank of China, it shows that the decline in the formal supply of credit in poor areas has led to a rise in rates of interest in informal credit markets and thus trapped more poor people in the debt cycle. Such a conclusion is for us a signal to draw attention to the indebtedness of rural people in Côte d'Ivoire. Thus, in this informal market, interest rates are relatively higher (Khalily \& Khaleque, 2013) and this could lead rural people into a permanent cycle of indebtedness if the funds obtained are not used to purchase production assets (agricultural inputs, equipment etc.). This assertion is in line with the work of Besley (1995) who finds that the debt should be used for the realization of initial investments that can increase productivity and thus improve the income and well-being of rural households. So, it emerges the thorny question of the use of resources from credits. To give some answers to our question, let's look at Table 9 below. This table allows us to make an imputation of the use of credits at two levels with, on the one hand, expenditures and, on the other, investments. Firstly, it is noted that health, food and other expenses (various ceremonies) account for 36.69\%, $22.6 \%$ and $22.41 \%$ respectively of the number of credits obtained by these rural dwellers. The cumulative total of these three expenditure items amounts to $81.7 \%$ of the total number of loans. Secondly, three pockets of investment are to be considered in the use of rural credit, namely education (investment in human capital), housing and equipment, which respectively have $10.14 \%, 1.07 \%$ and $2.58 \%$ of the total loans obtained. The share of investments in the total number of rural credits is $13.79 \%$, the rest being spent.

Table 12 Distribution of Credits by Source and Use

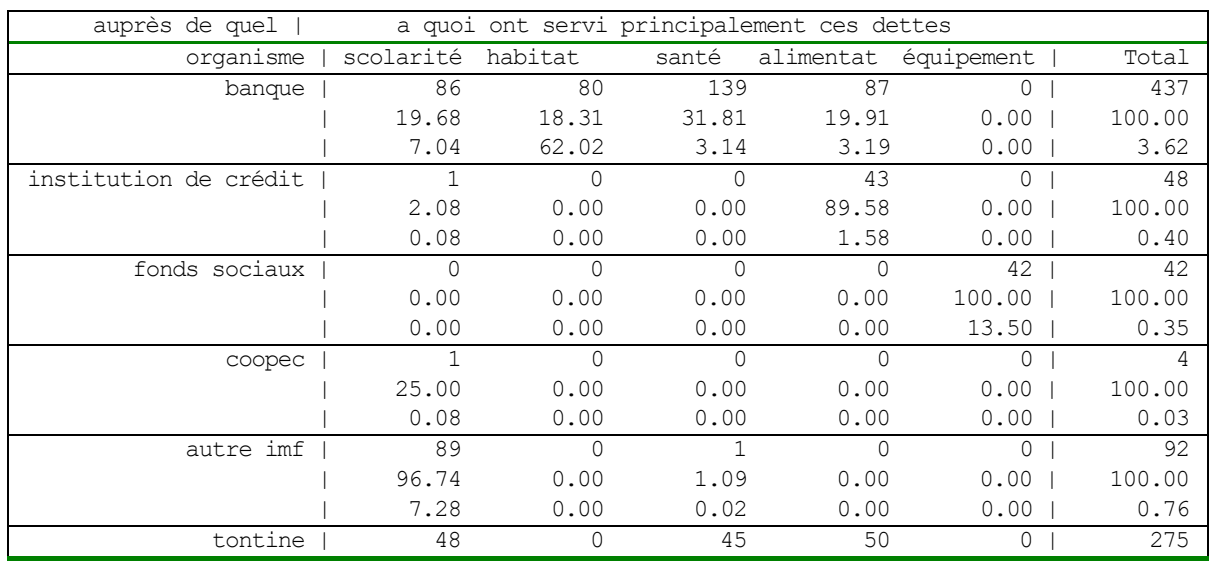




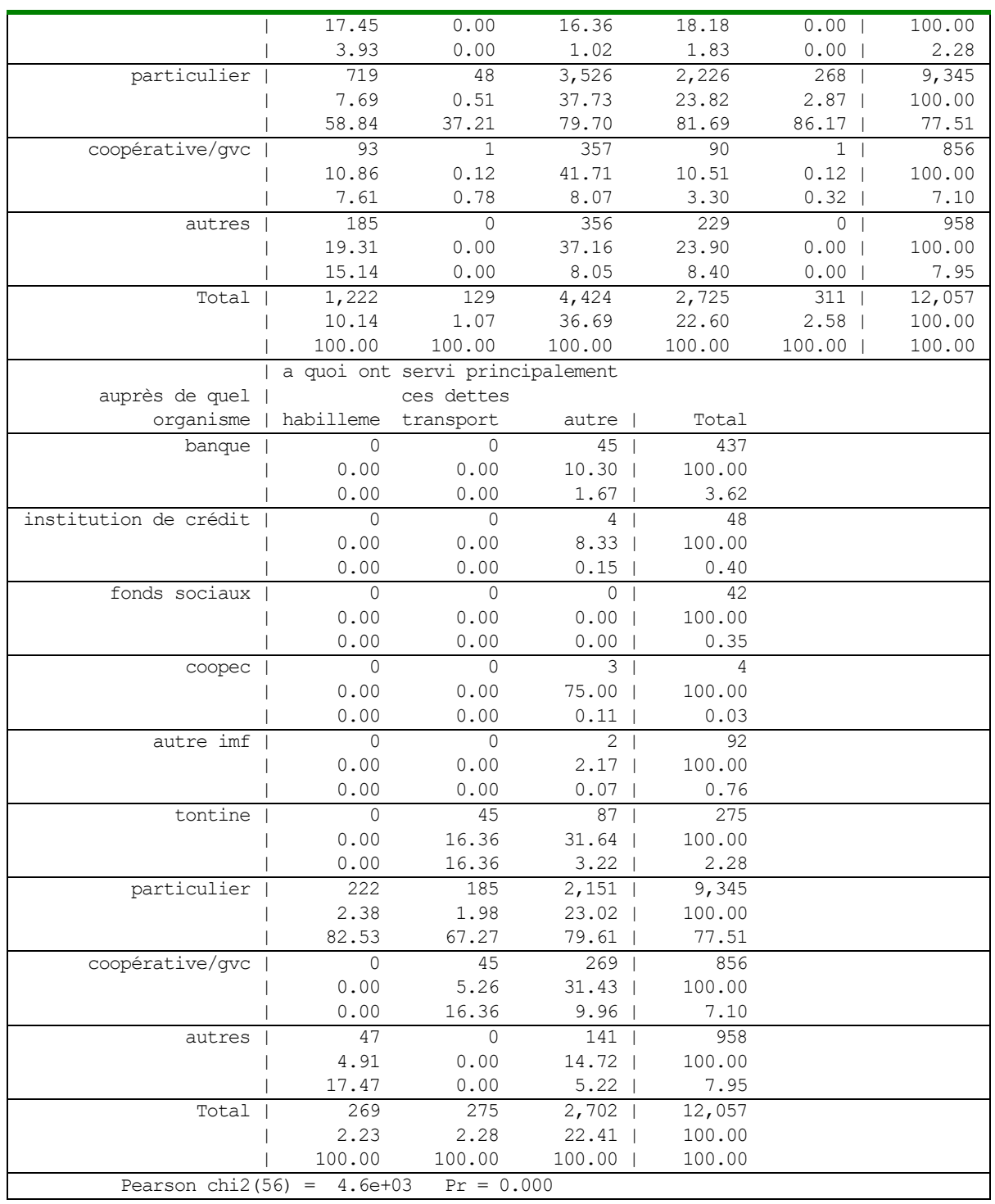

Source: Our calculations based on ENV2015 data

We can see that short-term investments in production account for only $3.65 \%$ of the total credits granted while investment in human capital (schooling of children) which is a very long-term investment mobilizes $10.14 \%$. Thus, even if it is only the quantity of credit and not the value of this credit, one can draw the conclusion that rural credit in Côte d'Ivoire is primarily informal and that it is mainly used for the realization of expenses and not for investments. These major facts cast doubt on the quality of credit on the one hand, and the use of this credit for productive purposes on the other. For our part, these facts explain the positive relationship between access to credit and the vulnerability of rural households in Côte d'Ivoire. Also, such widely available credits make rural households more vulnerable and could plunge them into a cycle similar to that mentioned by Wen Tie-yun (2001). 


\section{Conclusion}

At the end of our work we can mention that the analysis of the vulnerability of rural households to poverty in Côte d'Ivoire is of real interest because of the specificity of the economic, social and political environment in which this country has been plunged for a few decades. This research was designed to answer three research questions. The first question focuses on the difference between numbers of poor and those who are vulnerable to poverty. It has been concluded that $25.75 \%$ of the households in our sample are poor and $34.48 \%$ are vulnerable to poverty. Households vulnerable to poverty outnumber those who are poor. For Chaudhuri et al (2002), it is the presence of risks that explains this state of affairs. Thus, we confirm the first hypothesis of our study. In order to split our sample according to the status of poverty and vulnerability, we start by defining the future poor as being non-poor individuals but vulnerable to poverty (poor ex ante). These future poor represent $19.27 \%$ of the non-poor. The transient poor are individuals who are poor but not vulnerable to poverty. These represent $21.65 \%$ of the poor population. Finally, the structural poor are those who are poor and vulnerable to poverty. They represent $78.35 \%$ of the workforce of the poor. Vulnerability status analysis according to the level of education and business sector will allow us to answer the second research question. It should be noted that households headed by a chef in agriculture or commerce are more vulnerable than those headed by a chef operating in industry and services, all other things being equal. In addition, the achievement of at least secondary education by the head of household reduces the vulnerability of households regardless of the sector of activity in which he operates. The second and third hypotheses of our research are thus confirmed. Thus, one of the recommendations of this research would be the continuation of the government program to make the school accessible to all until the minimum age of 16 years. At this stage, all children of school age will have easily reached secondary education. On the third question of whether credit improves the vulnerability of rural households in Côte d'Ivoire, we answer in the negative. Credit unfortunately makes rural households even more vulnerable to poverty. On the one hand, it is the preponderance of the informal market in the provision of this credit, on the other hand the use of these credits to make expenditures and not the acquisition of productive assets, which would be the source of this rather rare relationship between vulnerability and demand for credit. The fourth hypothesis is therefore invalidated. In such a context, it would be appropriate to recommend more rural access to formal credit.

However, it can not be said with certainty that informal credit and the use made of credit by rural people justify this relationship between access to credit and vulnerability to poverty. This is a limitation of our study. It would therefore be wise to conduct research aimed at analyzing the influence of access to different sources of credit on vulnerability to poverty on the one hand and the impact of the use of credit on the same vulnerability.

\section{References}

Ajay, T., Rana, H. (2005), Conceptualizing and Measuring Poverty as Vulnerability: Does It Make a Difference?, ERD Policy Brief Series, 41, Manila: Asian Development Bank.

Alwang, J., Siegel, P., Jorgensen, S. (2001), Vulnerability: A View from Different Disciplines, Social Protection Discussion Paper, 0115, Social Protection Unit, Human Development Network, World Bank, Washington, DC.

Azam, S., Imai, K.S. (2009), Vulnerability and poverty in Bangladesh, Chronic Poverty Research Centre Working Paper, 141.

Barrientos, A. (2010), Vulnerability and Social Protection in Small Island States: The Case of Grenada, Social and Economic Studies, 59 (1/2). 
Bah, A. (2015), Estimating Vulnerability to Poverty using Panel data: Evidence from Indonesia, HAL archives-ouvertes, available at https://halshs.archivesouvertes.fr/halshs-00936199v3.

Beck, T., Demirgüc-Kunt, A., Peria, M.S.M. (2008), Banking Services for Everyone? Barriers to Bank Access and Use around the World, World Bank Economic Review, 22 (3), 397-430.

Besley, T., Coate, S. (1995), Group Lending, Repayment Incentives and Social Collateral, Journal of Development Economics, 46, 1-18.

Calvo, C., Dercon, S. (2013), Vulnerability to individual and aggregate poverty, Social Choice and Welfare, 41 (4), 721-740.

Chaudhuri, S., Jalan, J., Suryahadi, A. (2002), Assessing household vulnerability to poverty from cross-sectional data: A methodology and estimates from Indonesia, Department of Economics Columbia University, available at http://digitalcommons.libraries.columbia.edu/econ dp/117.

Chaudhuri, S. (2003), Assessing vulnerability to poverty: concepts, empirical methods and illustrative examples, Department of Economics Columbia University, available at

http://info.worldbank.org/etools/docs/library/97185/Keny_0304/Ke_0304/vuln erability-assessment.pdf.

Christiaensen, L.J., Subbarao, K. (2005), Towards an Understanding of Household Vulnerability in Rural Kenya, Journal of African Economies, 14 (4), 520-558, available at https://doi.org/10.1093/jae/eji008.

Diagne, A., Zeller, M. (2001), Access to Credit and its impacts on Welfare in Malawi, Research Report, 116, Washington D. C., International Food Policy Research Institute.

Ellis, K., Lemma, A., Rud, J.P. (2010), Investigating the impact of access to financial services on household investment, London, Overseas Development Institute.

Eswaran, M., Kotwal, A. (1990), Implications of Credit Constraints for Risk Behaviours in Less Developed Economies, Oxford Economic Papers, N-S, 42 (2), 473-482.

Grossman, M. (1972), On the Concept of Health Capital and the Demand for Health, Journal of Political Economy, 80 (2), 223-255, available at https://doi.org/10.1086/259880.

Institut national de la statistique (INS) (2015), Enquête sur les Niveaux de Vie des Ménages en Côte d'Ivoire, ENV2015.

Ministère de la Planification et de la programmation du Développement, Institut national de la statistique (INS) (2014), Recensement Général de la Population et de l'Habitat.

Jha, R., Dang, T., Sharma, K.L. (2009), Vulnerability to Poverty in Fiji, International Journal of Applied Econometrics and Quantitative Studies, 6 (1).

Khalily, M.A.B., Khaleque M.A. (2013), Access to Credit and Productivity of Enterprises in Bangladesh: Is There Causality?, Working Paper, 20, Institute of Microfinance, Dhaka.

Holzmann, R., Jørgensen, S. (2000), Social Protection as Social Risk Management: Conceptual Underpinnings for the Social Protection Sector Strategy Paper, Journal of International Development, 11, 1005-1027.

Ligon, E., Schechter, L. (2003), Evaluating Different Approaches to Estimating Vulnerability, Social Protection Discussion Paper Series, 0410, Social Protection Unit, Human Development Network, The World Bank, Washington DC.

Long, J.S., Freese, J. (2014), Regression Models for Categorical Dependent Variables in Stata, 3rd ed. College Station, TX: Stata Press. 
Milcher, S. (2010), Household vulnerability estimates of Roma in Southeast Europe, Cambridge Journal of Economics, 34, 773-792.

Nwanna, G. I. (1995), Financial Accessibility and Rural Sector Development / Accès Au financement et Developpément du Secteur Rural, Savings and Development, 19 (4), 453-491.

Novignon, J. (2010), Estimating household vulnerability to poverty from cross section data: an empirical evidence from Ghana, MPRA Paper, 39900, available at https://mpra.ub.uni-muenchen.de/39900/.

Novignon, J. (2012), Health and vulnerability to poverty in Ghana: evidence from the Ghana Living Standards Survey Round 5, Health Economics Review, 2 (11), available at https://doi.org/10.1186/2191-1991-2-11.

Ouoya, Z. M. (2018), Shocks, Access to Credit and Rural Households Resilience: An Evidence From Côte d'Ivoire, International Journal of Scientific and Research Publications, 8 (11), available at http://www.ijsrp.org/research-journal1118.php.

Pritchett, L., Suryahadi, A., Sumarto, S. (2000), Quantifying Vulnerability to Poverty: A Proposed measure, Applied to Indonesia, Policy Research Working Paper, 2437, Washington DC: The World Bank.

Raftery, A.E. (1995), Bayesian model selection in social research, Vol. 25 of Sociological Methodology, ed. P. V. Marsden, 111-163, Oxford: Blackwell.

Suryahadi, A., Sumarto, S. (2003), Measuring Vulnerability to Poverty in Indonesia Before and After the Crisis, paper presented at the 4th Annual GDN International Conference, organized by IPALMO, Cairo (Jan 21).

Tesliuc, E., Lindert, K. (2004), Risk and Vulnerability in Guatemala: A Quantitative and Qualitative Assessment, Social Protection Discussion Paper, 408, Washington DC: The World Bank.

Wen Tie-yun (2001), The Increasing Rural Usuries - the Current Situation, Problems and Policy Suggestions, Research Report Entrusted by the Monetary Policy Committee, the People's Bank of China.

Zeller, M., Schrieder, G., Von Braun, J., Heidhues, F. (1997), Rural Finance for Food Security for the Poor: Implications for Research and Policy, Food Policy Review, 4, Washington, DC: International Food Policy Research Institute. 